\title{
Exploring Doctoral Student Identity Development Using a Self-Study Approach
}

\begin{abstract}
The doctoral journey is as much about identity transitions as it is about becoming an expert in a field of study. However, transitioning from past and professional lives and identities to scholarly identities is not an easy process. Three doctoral students at various stages of completion engaged in self-study research to explore their emerging identities as doctoral student practitioners. Drawing on self-study and doctoral student identity research, as well as findings from our individual analyses, we explore how self-study can be used as an authentic and positive experience to help doctoral students understand their scholarly identity development. After describing the benefits of self-study research for doctoral student success, we provide practical guidelines for how to implement self-study research into existing doctoral programs.
\end{abstract}

\section{KEYWORDS}

self-study, doctoral socialization, doctoral study, doctoral curriculum, scholarly identity

The doctoral journey is as much about identity transitions as it is about becoming an expert of research and teaching within a discipline (Harrison, 2008; Jazvac-Martek, 2009; Pinto Zipp, Cahill, \& Clark, 2009; Wright, Lange, \& Da Costa, 2009). Doctoral students experience a number of identity transitions as they study, first becoming a doctoral student, then a doctoral candidate, and then an emerging scholar, and finally moving toward becoming a faculty member (Austin, 2002). However, transitioning from past and professional lives and identities is not an easy process; becoming a doctoral student and engaging in a life of scholarship can be a challenging and often frightening experience (Harrison, 2008; Jazvac-Martek, 2009; McAlpine \& Amundsen, 2009). The ease with which doctoral students transition into the academy can influence time to completion, overall attrition rates of a doctoral program, and the decision to enter the professoriate (Austin, 2002). Encouraging doctoral students to undertake self-study research to examine their work as doctoral practitioners and their ongoing identity transitions is one way to guide students through the challenges of doctoral study.

Self-study traditionally involves researchers examining themselves and their own practices using a systematic research process; the emphasis of the research is on the self 
as a practitioner (Samaras \& Freese, 2009). We three doctoral students enrolled in a Curriculum and Instruction $\mathrm{PhD}$ program engaged in a collaborative self-study. We examined our own practices and identity changes. While self-study research began with teacher educators, after having conducted this study, we argue that doctoral students are themselves practitioners in the academy and can therefore benefit from undertaking selfstudy research and examining their daily working practices. From our experience with this research, we argue that the systematic and critical approach of self-study inquiry is a valuable and currently under-utilized method for encouraging doctoral students to undertake traditional scholarship while critically reflecting on their doctoral experiences and identity development.

\section{LITERATURE REVIEW}

Learning and identity development are closely connected (Baker \& Lattuca, 2010; Barnacle \& Mewburn, 2010; Janke \& Colbeck, 2008). Upon entering a doctoral program, students are exposed to multiple academic and scholarly cultures and begin to undertake a number of identity transitions concurrently. From the start of their study, doctoral students are striving to develop the identities of a doctoral student, a scholar and member of the academy, and an affiliate of a particular discipline (Austin, 2002; Austin \& McDaniels, 2006; Baker \& Pifer, 2011; McAlpine \& Amundsen, 2009). The ease with which doctoral students begin to internalize and enact new identities may influence whether they persist with their studies or drop out at the eleventh hour (Baker \& Pifer, 2011). McAlpine and Amundsen (2009) suggest that taking an active role in research and becoming a part of a discipline provides a positive identity experience for doctoral students, and we argue that self-study is a systematic and independent research experience that can provide such an experience for doctoral students.

\section{Examining the culture of doctoral studies}

Culture and identity are interconnected; as students interact with others and engage in tasks within a specific academic and disciplinary culture, they begin to develop roles and identities within that culture. Academia represents a site of many intersecting cultures (Holley, 2011), and doctoral students have to negotiate contexts that include the institution, their specific college, their department, their discipline, their supervisor's perspective on the discipline, and various contexts that exist within individual departments. Gaining a solid grasp of the academic culture can influence student retention; therefore, if students do not learn the rules governing behavior within the academic and doctoral culture, they may well not make it through doctoral studies.

Self-study acknowledges the influence of the local "context" or culture in which the researchers work and live, which is often "hidden from" (Pinnegar \& Hamilton, 2009, p. 81 ) them even as it influences practice. Self-study research considers the culture of the environment of practice, how "the context shapes and constrains [their] practice," and how through their own "actions [they] shape and change the context in which [they] act" (Pinnegar \& Hamilton, 2009, p. 81). Encouraging doctoral students to undertake selfstudy may assist them in uncovering local cultural contexts that influence daily practice and identity development. Learning environments, though, are not only made up of institutional structure, physical environment, and hidden messages; learning environments 
are made up of various groups of people, and self-study research also provides doctoral students with opportunities to build important social connections.

\section{Self-study as a catalyst for peer interaction}

The literature on doctoral student socialization highlights the importance of students undertaking self-reflection and dialogue with peers (Ward \& West, 2008). Self-study also concentrates on dialogue and collaboration with others to construct knowledge (Coia \& Taylor, 2009). In this way, self-study provides a perfect opportunity to encourage collaboration between peers (and other groups) in doctoral programs. Doctoral peers understand what other students are going through; they are also transitioning into new roles, and while these experiences and transitions will be unique for each person, peers can provide support to each other through times of socialization and identity transition (Baker \& Lattuca, 2010; Baker \& Pifer, 2011). Baker and Pifer (2011) call the support that advanced doctoral students give to less advanced students, who then learn, develop, and offer their support to new doctoral students, "the family tree effect" (p. 15).

Interactions with others are fundamental to self-study research (LaBoskey, 2004), providing an excellent frame within which to encourage a structured family tree to doctoral students. The emphasis on "intentional collaboration" (Pinnegar \& Hamilton, 2009, p. 19) in self-study allows doctoral students to not just reflect on their experiences with their social networks and how those networks might influence their identity development, but also provides an avenue for encouraging peer interaction between doctoral students as part of an authentic research project.

\section{Examining the academic/doctoral self}

Research indicates that doctoral students feel a particular sense of pleasure and agency when they work on authentic scholarly activities, for example when they can make real contributions in meetings, take part in research with faculty, or even express how they intend to get more involved in future academic roles (McAlpine \& Amundsen, 2009). Another way to exercise agency is to take on elements of a cultural group to see how they fit with internal values before transitioning too deeply into a specific identity; students essentially try on temporary identities (Baker \& Lattuca, 2010) as they move through academia. However, it is not easy to try on different selves without first examining our existing values and beliefs. Self-study allows doctoral students to come to a greater understanding of self by examining their practice (Pinnegar \& Hamilton, 2009); in other words, doctoral students can consider their own values and beliefs through an examination of their daily experiences as doctoral students and emerging scholars. Using this approach, it is also possible for students to examine their values over time and begin to see more clearly how the overlapping and sometimes contradictory cultural groups in academia influence identity.

Usually the impetus to undertake self-study must come from researchers' own motivations and craving to understand themselves (LaBoskey, 2004). However, because of the benefit to doctoral students undertaking self-study, we believe it is important for doctoral coordinators and faculty to invite doctoral students to take part in self-study research. No one can be forced to undertake self-study; however, the crucial elements of self-study such as collaboration with peers, examination of practice, systematic research, 
and dissemination of results are generally common elements found somewhere in the doctoral curriculum, even if they are not always framed together in a self-study project. After undertaking our own self-study research project outlined below, we believe that other doctoral students will want to undertake these authentic activities while examining their own identity transitions as doctoral students and emerging scholars.

\section{STUDY DESIGN}

We three doctoral students undertook self-study research to examine our own practice as well as explore how the process might assist others in the complex and varied identity developments that occur during doctoral study. The main research question was How do my daily experiences and practices as a doctoral student influence my identity as a doctoral student and emerging scholar?

\section{Self-study research design}

The purpose of self-study is to stimulate questions and strive for clarifications (LaBoskey, 2004). While self-study research often focuses on teacher educators as they work in collaboration with student teachers (Feldman, Paugh, \& Mills, 2007), we used it as a framework for doctoral student self-exploration. Doctoral students are practitioners in contexts that vary according to their unique life situations, but they are usually immersed in doctoral study 24 hours a day, seven days a week. We decided that doctoral students are therefore practitioners within the context of the academy and that a self-study framework may provide us, and others trying to understand doctoral student identity, insight into our daily practices.

Self-study is not merely a narcissistic endeavor with little structure; self-study is systematic and provides an orderly way to examine our own practice (Samaras \& Frees, 2009). There is no single way to conduct a self-study; instead the approach allows flexibility for researchers to adapt methods to the particular research problem they wish to address. Even with this flexibility, there are some key components that should be included in a self-study design. LaBoskey (2004) outlines five elements that are fundamental to any self-study inquiry:

1. The practitioner, in this case the doctoral student, should be both the researcher and the researched.

2. The goal of the research is to improve oneself in some way.

3. At various points in the self-study process, the practitioner/researcher interacts with others.

4. Self-study is qualitative and usually involves multiple methods of data collection.

5. The researcher should corroborate findings by sharing and disseminating them.

In our study, the doctoral students acted as both the researchers and the researched as we examined our own experiences and identity development. While our self-study was not about "improvement" in the sense that LaBoskey likely meant in relation to teacher practice, we argue that conducting successful research in doctoral work is a catalyst for encouraging positive identity experiences and improving our work as emerging scholars. By allowing doctoral students to experience a research project concentrating on the self with results that can be disseminated at conferences and in publication, we empower 
doctoral students to become both "researchers and constructors of knowledge" (Samaras \& Freese, 2009, p. 9).

\section{Context of study}

The site for this study was a Curriculum and Instruction (C\&I) $\mathrm{PhD}$ program in a four-year, public institution in the USA. The $\mathrm{PhD}$ program is organized into two major parts: a coursework phase in which students complete 60 credit hours beyond the master's degree, and a dissertation phase (candidacy) in which students conduct research related to their dissertation. At the end of the coursework phase, students complete a comprehensive exam, which can be taken at home over the course of eight weeks or onsite over two days. Students then meet with their advisor and committee to defend their comprehensive exam responses before submitting a dissertation proposal. Finally, the dissertation proposal is also defended to the advisor and committee before doctoral students can embark on dissertation research.

All doctoral students have in common the fact that, when they are admitted into a new program, they endeavor to become part of the culture of an institution, program, and a specific field of study. The C\&I program has a specific culture as demonstrated by the expectation of the program that most doctoral students are preparing to become future higher education faculty. The program also offers a wide range of specializations, such as literacy, teacher education, math, and science. In this way, many doctoral students in the program have to navigate multiple and overlapping cultures as they study-the culture of the C\&I program and the culture of a specialization program and discipline. There is no guarantee that the two academic disciplines have the same expectations and values, or that the two cultures will coincide seamlessly. Students in our program have to navigate competing expectations and cultures within one overarching program. As Table 1 indicates, the three participants in this study were at various levels of coursework and candidacy during the study, and each was studying for a different specialization within the field of C\&I.

Table 1. Self-Study Participants

\begin{tabular}{llll} 
& CHAD & KAREN & RACHEL \\
\hline Age Range & $40-45$ & $50-55$ & $30-35$ \\
\hline Gender & M & F & F \\
\hline Program & $\begin{array}{l}\text { Curriculum \& } \\
\text { Instruction-Teaching } \\
\text { Studies }\end{array}$ & $\begin{array}{l}\text { Curriculum \& } \\
\text { Instruction-Literacy }\end{array}$ & Instruction-General \\
\hline Stage of Study & Coursework: & Coursework: final & Candidacy \\
& 33 credits (11 courses) & semester & Completed coursework \\
& & & Currently proposing \\
\hline $\begin{array}{l}\text { Graduate Assistant (GA) } \\
\text { or Instructor (I) }\end{array}$ & I & GA & dissertation topic \\
\hline $\begin{array}{l}\text { Full-Time (FT) or } \\
\text { Part-Time (PT) }\end{array}$ & PT & FT & GA \\
\hline
\end{tabular}




\section{DATA GENERATION AND ANALYSIS}

Multiple methods of data generation are appropriate in self-study research, and they should closely adhere to the research questions that guide the study (Louie, Drevdahl, Purdy, \& Stackman, 2003). Although data were collected in this study from all three participants in a similar way, there was space for participants to adjust methods to our personal preferences. The following list shows the systematic steps of data collection and analysis used in the study:

- After meeting to discuss the overarching research questions, each of us began to keep a personal journal (Harris, Freeman, \& Aerni, 2009) to collect thoughts and reflections related to doctoral experiences over a four-month period. Personal journals were used to encourage self-reflexivity about the research process (Drake \& Heath, 2010). These journals were not prescriptive in nature; we could keep journals in any way we saw fit. Karen kept hand-written notes and journals, Rachel typed reflective journals, and Chad created art sculptures alongside written and audio journals.

- Activity logs describing a week of doctoral and academic-related activities were recorded twice each month for four months to explore the daily lived experiences of doctoral students (Hopwood, 2011). It was felt that having some idea of common daily activities for each of us would help to contextualize the personal reflections.

- Critical Incident Reports (CIR) were recorded when we felt an important event had taken place. Brookfield (1995) describes Critical Incident Questionnaires (CIQ) as a tool to encourage students to reflect on meaningful events that have occurred during class - those "vivid happenings that for some reason people remember as being significant” (Brookfield, 1995, p. 114). Brookfield primarily uses CIQs to strive to understand how teaching influences the learning and emotions of students. However, CIQs can also make visible "blind spots" (p. 122) in educators' approaches, helping educators examine their practices during sessions and then reflect on how their beliefs and values intersect with that practice. We used CIRs in a similar way in self-study as we began to examine the decisions we made everyday as practitioners and reflect on why we made those decisions (Goodell, 2006). The purpose of the CIR was to make the familiar events of doctoral study strange (Feldman et al., 2007; Goodell, 2006). In comparison to the personal journals, the format of the CIR was prescribed to help encourage deep reflection in a systematic way. As well as noting specific details about the important event (date, time, participants, and contextual details), we were asked to consider the event, our actions in the event, internal thoughts and emotions, the assumptions and beliefs suggested in our external actions, where there values and beliefs come from, how congruent actions were with values and beliefs, and consequences of actions. These questions helped uncover any inconsistencies between our values and beliefs and our actions as doctoral students and emerging scholars.

- Ongoing dialogue occurred regularly among each of us and between us and faculty critical friends. Interacting and collaborating with others and striving to create a community of practice are crucial in self-study (Coia \& Taylor, 2009; LaBoskey, 2004). Dialogue with others is also important in this study because part of identity development comes from social interaction with others (Coia \& Taylor, 2009). 
We participated in two formal meetings, as well as informal meetings, discussions, email, texting, and Facebook discussions. The first meeting was a traditional roundtable as we built on each other's comments and questions. The second meeting followed an adapted fishbowl structure whereby we anonymously submitted questions and comments related to the self-study process, which were then randomly selected and discussed by all three of us. All communications were recorded, transcribed, and then provided to us for further reflection. All meetings were analyzed alongside the journals, CIRs, and activity log data.

\section{Analysis}

Self-study is a "cyclical" research approach (Coia \& Taylor, 2009; Harris et al., 2009), which requires a back-and-forth process. Data generation and analysis took place simultaneously (Clandinn \& Connelly, 2005; Creswell, 2007; Hatch, 2002; Hesse-Biber \& Levy, 2006; van Manen, 1990), so we could communicate with each other about new insights throughout the study. What this meant in practice was that as we reflected and journaled individually, we were also reflecting on what our colleagues had written and how the reflections intersected. Once we started to meet together as a group, the conversations were transcribed and then analyzed and reflected on in our subsequent journals. In self-study, "analysis is collaborative, reflective, and participatory" (Coia \& Taylor, 2009); therefore we examined our own data for themes related to identity development before we undertook group conversations about those themes with each other. We analyzed our data individually before analyzing across the three data sets so that we could identify broad themes in the research. Our process was as follows:

- The constant-comparative approach was used to open-code the data and examine broad themes (Glauser \& Strauss, 1967). The open coding involved each of us reading, re-reading, and coding our own data before meeting with each other to discuss findings and similarities and differences (Harris et al., 2009).

- During analysis, we each created, defined, and labeled categories from our own data (Hesse-Biber \& Levy, 2006; Rubin \& Rubin, 2005) and sent these to the group for review and reflection.

- We then examined all the categories we had created together in relation to our own student identities.

- When the data collection was complete, all three of us reviewed analyses and summaries from our colleagues and examined the full spectrum of data across sets to uncover common themes pertinent to doctoral student identity and self-study.

- Finally, the data as a whole were examined to explore the appropriateness of selfstudy in encouraging critical self-reflection and identity development in doctoral students.

\section{FINDINGS AND INSIGHTS}

Findings from the study highlighted themes related to maintaining multiple identities and struggling with letting go of old identities, connecting with others in doctoral studies, and the importance of self-reflection. Interestingly, though, our primary finding was that we as doctoral students lack self-efficacy related to our success as doctoral students and emerging scholars. We provide examples of these themes before providing a 
more detailed discussion of self-inefficacy and suggesting ways we can use self-study to disrupt an underlying lack of confidence in doctoral students.

\section{Maintaining multiple identities}

Doctoral students develop and sustain multiple identities at once, such as practitioner, student, and emerging scholar. As doctoral students strive to become successful scholars and future academics, there may be a reluctance or sense of loss as they place less emphasis on previous identities. This was seen in our study especially from Chad and Karen, who both have strong existing identities as educators, while lifelong learner Rachel struggled less. Chad explained,

Duality of identity is best described as how I am a student, instructor, spouse, doctoral student, supervisor, researcher, tennis player, gay male, a 40-something etc. in this process. I can't assume one of these identities because the others are ever-present and pulling me in a million directions. There are times when I can trade-off temporarily one for the other, however, in moments when I am quiet or figuring out what I need to be doing, resentment is sometimes present.

\section{Connecting with others}

Dialogue and collaboration with others seemed to provide a sense of reassurance for all of us: we realized during the study that we are not alone struggling with issues of identity, as demonstrated when Karen wrote, "the support and collegiality I have experienced has been essential for me." Rachel too noticed the importance of connection when she wrote,

interaction, or lack of interaction, was seen most visibly in my activity

logs. There were whole weeks where I could not identify peers or super-

visors that I had interacted with. I am at a distinct point in the doctoral

process where classes have stopped and independent research is paramount.

At one point I talk about this in my journals as "isolating."

\section{Self-reflection}

Identity transitions are complicated and multi-layered processes. Self-study provided much needed space, time, and even community to think through our scholarly processes, identities, and who we are becoming. Chad reflects, "sometimes you cannot be so focused on the actual product, but the process has got to be fundamental. Because you repeat your processes, you don't repeat the product, and if your process is broken then you're going to run into trouble," while Karen noted, "I even reflect upon the need for some type of group like this one to be implemented early in the doctoral program. The support and collegiality I have experienced has been essential for me."

While some of the findings from our data were positive, for example the encouraging influence of connecting with peers, there was a worrying and prominent theme from all three participants' data related to a sense of self-inefficacy.

\section{Self-inefficacy}

There were four major disruptions to identity development related to self-inefficacy in the data: comparison to others, fear of the future, not knowing where we fit, and fear 
of failure. While we have termed this theme self-inefficacy, others may consider it an "imposter syndrome," a term used to describe "feelings of guilt and failure" by those who, "despite academic credentials and praise from peers, do not always experience an internal sense of self" (Gardner \& Holley, 2011, p. 80). While imposter syndrome may be more closely associated with underrepresented groups of students in higher education (Gardner \& Holley, 2011), the diversity of characteristics of the doctoral students in this study suggests this could be an issue for any doctoral students.

Self-inefficacy in the data seemed to stem primarily from internal sources rather than external experiences. Bandura (2006) explains the importance of the internal world where "people live in a psychic environment largely of their own making" (p. 165). The importance of the internal world was seen throughout all of our findings as we communicated an internal world of fears and worries related to our abilities as doctoral students. In Karen's reflection on the study she notes that, "fear was reflected in the ways in which we talked about feeling unprepared for various tasks during our programs and in comparing ourselves to others."

Self-inefficacy also influences how we choose to act and behave. Chad specifically noted how fear could be debilitating: "fear is how I have categorized moments when anxiety would step in or the idea of failure would keep me from actually doing what must be done," and all three of us communicated feeling like a "fraud" on multiple occasions. The internal environment that we live in is very much connected to our agency and how we enact it. Agency is not simply about taking actions; it resides in the choices we make about whether to take action or not (Bandura, 2006). Rachel and Karen specifically talked a great deal about being procrastinators. If we consider that when we procrastinate, we are both enacting agency and choosing not to work (even if this isn't a conscious decision), it becomes more likely that our self-inefficacy is actually influencing our actions. Karen shows insight into this point and the way self-inefficacy might influence her decision to procrastinate when she asks, "do I procrastinate because I'm afraid, or am I afraid because I procrastinate?"

Bandura (2006) observes that "most human functioning is socially situated" (p. 165), and in this way we see a connection to the doctoral identity literature related to cultural context and connections with others. While our own self-reflections, intentions, and previous experiences influence our agency, so too does our environment, the situational context, and the people we interact with (Bandura, 2006). Chad notes the influence that faculty and supervisors have over our assessment of our self-efficacy when he acknowledges that

it is sad and weird that a professor can make one comment in a day of a million words and that one comment lingers and sits on your shoulder all day, the next day, and on and on .... it lingers and makes you question yourself.

Once this kind of doubt has crept into our minds, it can have a profoundly negative influence on the way we enact agency and, therefore, can disrupt identity development. Bandura (1982) concludes that even when people know what to do to succeed, they may not do it because "those who judge themselves ineffacious in coping with environmental demands dwell on their personal deficiencies and imagine potential difficulties as more formidable than they really are" (p. 123). The question then becomes: how we can help doctoral students step outside of their inner world of self-doubt and fear and 
move into a world where they enact the identities of successful doctoral students and emerging scholars?

\section{Interrupting self-inefficacy}

As well as self-inefficacy, we also noted key elements that seemed to positively influence our identities and disrupt a preoccupation with inefficacy. For example, Hopwood (2010) explains the importance of connections that students make with others, and any discussion of interactions with others was primarily a positive element in our data. All three of us discussed positive "embodied" (Hopwood, 2010, p. 109) connections with colleagues. For example, Chad noted that "there is something about walking into the $\mathrm{G}$ [raduate] A[ssistant's] office and seeing familiar faces, some smiling and some not even knowing that someone has entered ... feels good walking in and knowing we all have a ticket on the crazy ride with ups and downs, quick turns, bumps, broken safety belts and countless loops."

We have already noted the close interconnection between agency and self-inefficacy; however, the data also demonstrated specific times where doctoral student agency resulted in more positive outcomes. For example, when we discussed working on research projects we had a particular interest in, such as out-of-class assignments, there was a sense of pleasure and satisfaction. Karen states, "I have discovered that I am excited and happiest when I am able to work on research and projects related to me line of inquiry and that keep me moving forward. I get 'lost' in that work and don't feel any stress.' Rachel mentioned conferences and article submissions more frequently than the other participants, perhaps because she is slightly further along in the stages of doctoral study, and often these were related to a sense of success and feeling like a 'real' scholar, such as when she was accepted to a conference.

Finally, the data explicitly mentioned the benefit of undertaking self-reflection. While much of our reflections related to an internal world where self-doubt and feelings of selfinefficacy ruled, the very nature of the self-study provided impetus for us to engage our agency to both reflect internally on how our self-doubts were influencing our actions and to connect with others and step outside of the inner world. Karen felt strongly that the self-study was helpful for her and would be something that could benefit other doctoral students: "I even reflect on the need for some type of group like this one to be implemented early in the doctoral program. The support and collegiality I have experienced has been essential for me." When we had to cancel one of our self-study group discussions because of illness in the group, Chad reflected that "I was a little down ... it was the idea of having friends over to talk and discuss our studies, to get more intimate about the week and what was happening in our lives." Rachel also highlighted the benefits of reflection in self-study, noting in her journal after the first group meeting that

\section{I do see something helpful to me and other doctoral students here. And that is the distance. When I was in the meeting with Chad and Karen I was mentally having to deal with a lot.... I didn't have time to consider my emotions or my lack of confidence. Sitting here and writing this meandering reflection has given me that much needed distance.}

The data illustrate that self-study was viewed as a positive experience in terms of identity development by all of us, especially because it provided us with a context to use 
our agency to connect with others and reflect on how our internal worlds and imaginary connections might influence our doctoral experiences and identity development. Selfstudy as a scholarly activity encompasses all three elements that we found disruptive to debilitating feelings of self-inefficacy, namely connection with others; the opportunity to partake in real-world, authentic research that can be submitted for conferences and publications; and a chance to undertake self-analysis of our multiple identities. The question, then, is how to best implement self-study research into the variety of doctoral curricula around the world?

\section{IMPLEMENTING DOCTORAL SELF-STUDY RESEARCH}

Self-study research is a qualitative approach that consists of elements similar to other qualitative forms of inquiry, such as narrative or phenomenology (Pinnegar \& Hamilton, 2009). However, there are some elements unique to self-study, which because of their fundamental nature should be included in any self-study project implemented in doctoral programs. The first essential characteristic is that self-study concentrates on the ontology of the person undertaking the study (Pinnegar \& Hamilton, 2009). More specifically, a self-study for doctoral students must encourage the participants to examine what they believe to be real and question "the taken for granted assumptions" (Pinnegar \& Hamilton, 2009 , p. 7) of doctoral study. In other words, doctoral students need to investigate their ways of being in the world and how this influences their daily practice.

Examining daily practice is an approach and habit that can benefit doctoral students who intend to enter the academy as professors and those who intend to use their qualifications outside of education. Many professions, such as those in the health and caring fields, require practitioners to reflect on and understand their own practice as part of their professional development, while others, such as administrators, can utilize their experiences with self-study to guide and assist colleagues and employees to evaluate and reflect on their daily practices. Whenever we move into a new position in life, we must negotiate our existing identities as we encompass new roles (Baker \& Pifer, 2011). The benefits of self-study have the potential to influence life and employment both inside and outside the academy as it encourages an understanding of our values and beliefs and how they influence us day-to-day.

The second defining characteristic of self-study is the emphasis on "dialogue" as a way to begin to see the world and the way we act within it (Pinnegar \& Hamilton, 2009; Samaras \& Freese, 2009). While many qualitative approaches highlight the importance of communication and interaction, "self-study researchers engage in dialogue, recognizing it as the basis from which they assert the authority of the claims they make and as a way to expose the ontological understandings and their practical actions" (Pinnegar \& Hamilton, 2009, p. 77). Another crucial element of self-study is that it should be a voluntary endeavor in which people have a particular interest in learning about themselves (Samaras \& Freese, 2009). One way to align with this would be to offer a self-study project to doctoral students as an optional activity. However, we argue that doctoral students, especially early career doctoral students, may not be able to see the benefits of self-study on their academic development until they begin to undertake such research.

There are of course a number of ways a self-study project could be implemented in doctoral programs. Instead of suggesting a single strategy, we provide suggestions for key elements that should be included in any doctoral self-study project. As long as the funda- 
mental elements of a self-study methodology are systematically designed into a strategy, we believe the outcomes should be beneficial to all doctoral students.

1. Allow a self-study research group to form naturally (whenever possible). Selfstudy requires open reflection and honesty, which requires trust between the doctoral students who will work together. We suggest that asking students to create their own team of self-study researchers is ideal. However, we also understand that this may not always be possible. For example, students who are particularly interested in taking part in self-study may not know other students who would also like to be part of the endeavor. Similarly, if doctoral supervisors have invited students to take part in a self-study class project to demonstrate the usefulness of examining one's practice, there may need to be more structure behind the creation of teams. One way to compromise when considering the creation of self-study research groups is to match newer doctoral students, "newcomers," with more experienced, "old timer" doctoral students (Lave \& Wenger, 1991). This approach can be beneficial when introducing doctoral students to the kind of deep and critical self-reflection needed for an examination of identity. While the trust and close collaboration essential to self-study may not be naturally available at the start with this type of group, a more experienced doctoral student versed in self-study can help to nurture trust over time and guide newer students through the self-study approach. This student can act as a kind of self-study advisor for each group and then take a step back as and when the group becomes more cohesive.

2. Encourage students to explore different forms of journaling. In our study, Chad's journaling was more art-based, Karen used hand-written reflections, and Rachel's thoughts were more like reflective essays. Doctoral students are often encouraged to reflect and journal, both in their role as students and as researchers, but in the authors' experience there is less emphasis on encouraging doctoral students to try different kinds of journaling and providing space for them to uncover a method of reflection that is best for them.

3. Complete regular Critical Incident Reports. CIRs provide a systematic framework for doctoral students to examine key experiences in their doctoral journey. Significantly for self-study, CIRs encourage doctoral students to question their ontology and reflect on the values and beliefs that influence the way they act (or do not act) in various situations.

4. Schedule regular meetings with the research team. Collaboration and dialogue are crucial in self-study research, and the doctoral student identity literature also highlights the importance of peer interaction for identity development. In our experience, however, time-crunched doctoral students are more likely to take part in peer interactions that are built into the formal curriculum. We suggest that regular meetings be arranged as a requirement of the project.

5. Work to publish and disseminate the results of the study. The doctoral identity literature suggests that authentic scholarly activities are crucial for identity development. This kind of self-study project cannot be conducted for the sake of it. Without a defined goal for analysis and dissemination at the end of the project, the benefit to identity development is lost, and the project counters the self-study 
framework, which values the distribution of findings. Students must explore ways to publish their findings throughout the study.

How individual coordinators decide to implement a self-study project for doctoral students will depend on a variety of factors. By following the suggestions listed above, any self-study will follow the essential framework of the methodology, as well as the guidance from the doctoral student identity literature.

\section{CONCLUSION}

Upon entering a doctoral program, students are exposed to multiple academic and scholarly cultures and thus begin to undertake a number of identity transitions simultaneously. From the start of their study, doctoral students are striving to develop the identity of a doctoral student, a member of the academy, and an affiliate of a particular discipline (Austin, 2002; Austin \& McDaniels, 2006; Baker \& Pifer, 2011; McAlpine \& Amundsen, 2009). However, creating new identities and gaining confidence in them while also maintaining previous identities is a difficult process. Because of the high attrition and time to completion rates in doctoral education today (Gardner 2007; Walker, Golde, Jones, Bueschel, \& Hutchings, 2008), it is crucial that we assist doctoral students through their identity transitions in any way that we can.

Self-reflection and dialogue with peers are both essential to learning and identity development. Based on our own experiences undertaking a self-study of our doctoral practice, we propose that asking doctoral students to undertake self-study research provides a systematic and authentic framework from which doctoral students can begin to reflect on their various identities and ways of being in the academic world. A self-study project as an integral part of the doctoral curriculum provides a structured space for doctoral students to engage in continuous dialogue with peers and practice much needed reflection, research, and publishing skills. Based on the self-study and doctoral literature, coupled with our own experiences of self-study scholarship, we have suggested criteria that can guide doctoral program coordinators and faculty as they strive to create experiences to socialize doctoral students to the academy, and encourage students to reflect on their emerging identities as doctoral students and scholars (Austin, 2002). Because "identity is a central concern in self-study of teaching practice" (Coia \& Taylor, 2009, p. 4 ), we argue that utilizing self-study to encourage students to examine their daily experiences and underlying values, beliefs, and assumptions will assist doctoral students in transitioning to confident scholars.

Rachel Foot is a doctoral candidate at Kent State University (USA), studying the influence of hidden curriculum on doctoral student experience.

Alicia R. Crowe is an Associate Professor of Social Studies Education and Teacher Education at Kent State University (USA).

Karen Andrus Tollafield is a retired teacher and doctoral candidate at Kent State University (USA), studying expressive outlets for LGBTQ identified youth.

Chad Everett Allan is a doctoral student, instructor and teaching supervisor studying teacher evaluation, assessment and identity. 


\section{REFERENCES}

Austin, A. E. (2002). Preparing the next generation of faculty: Graduate school as socialization to the academic career. The Journal of Higher Education, 73(1), 94-122.

Austin, A. E., \& McDaniels, M. (2006). Preparing the professoriate of the future: Graduate student socialization for faculty roles. In J. C. Smart (Ed.), Higher education handbook of theory and practice, Vol. XXI (pp. 397-456). New York, NY: Agathon.

Baker, V. L., \& Lattuca, L. R. (2010). Developmental networks and learning: Toward an interdisciplinary perspective on identity development during doctoral study. Studies in Higher Education, 35(7), 807-827.

Baker, V. L., \& Pifer, M. J. (2011). The role of relationships in the transition from doctoral student to independent scholar. Studies in Continuing Education, 33(1), 5-17.

Bandura, A. (1982). Self-efficacy mechanism in human agency. American Psychologist, 37(2), 122-147.

Bandura, A. (2006). Toward a psychology of human agency. Perspectives on Psychological Science, 1 (2), 164-180.

Barnacle, R., \& Mewburn, I. (2010). Learning networks and the journey of 'becoming Doctor.' Studies in Higher Education, 35(4), 433-444.

Brookfield, S.D. (1995). Becoming a critically reflective teacher. San Francisco: Jossey-Bass.

Clandinn, D. J., \& Connelly, F. M. (2000). Narrative inquiry: Experience and story in qualitative research. San Francisco, CA: John Wiley \& Sons.

Coia, L., \& Taylor, M. (2009). Co/autoethnogrpahy: Exploring our teaching selves collaboratively. In D. L. Tidwell, M. Heston, L. Fitzgerald (Eds.), Research methods for the self-study of practice: Self-study of teaching and teacher education practices (pp. 3-16). Netherlands: Springer.

Creswell, J. W. (2007). Qualitative inquiry \& research design: Choosing among five approaches. $\left(2^{\text {nd }}\right.$ ed.). Thousand Oaks, CA: Sage.

Drake, P., \& Heath, L. (2011). Practitioner research at doctoral level: Developing coherent research methodologies. New York, NY: Routledge.

Eisner, E. (2002). The Educational Imagination. On the design and evaluation of school programs (3rd ed.). Upper Saddle River, N.J.: Prentice Hall.

Feldman, A., Paugh, P., \& Mills, G. (2007). Self-study through action research. In J. J. Loughran, M. L. Hamilton, V. K. LaBoskey, \& T. Russell (Eds.), International Handbook of Self-Study of Teaching and Teacher Education Practice (pp.943-977). Springer.

Gardner, S. K. (2007). "I heard it through the grapevine": Doctoral student socialization in chemistry and history. Higher Education, 54(5), 723-740.

Gardner, S. K., \& Holley, K. A. (2011). "Those invisible barriers are real": The progression of first-generation students through doctoral education. Equity \& Excellence in Education, 44(1), 77-92.

Glaser, B. G., \& Strauss, A. L. (1967). The discovery of grounded theory: Strategies for qualitative research. Chicago, IL: Aldine Publishing Company. 
Goodell, J. E. (2006). Using critical incident reflections: A self-study as a mathematics teacher educator. Journal of Mathematics Teacher Education, 9, 221-248.

Harris, J. B., Freeman, T. L., \& Aerni, P. W. (2009). On becoming educational researchers: The importance of cogenerative mentoring. Mentoring \& Tutoring: Partnership in Learning, $17(1), 23-39$.

Harrison, R. L. (2008). Scaling the ivory tower: Engaging emergent identity as researcher. Canadian Journal of Counseling, 42(4), 237-248.

Hatch, J. A. (2002). Doing qualitative research in education settings. Albany, NY: State University of New York Press.

Hesse-Biber, S., \& Leavy, P. (2006). The practice of qualitative research. Thousand Oaks, CA: Sage.

Holley, K. A. (2011). A cultural repertoire of practices in doctoral education. International Journal of Doctoral Studies, 6, 79-94.

Hopwood, N. W. (2010). A sociocultural view of doctoral students' relationships and agency. Studies in Continuing Education, 32(2), 103-117.

Hopwood, N., Alexander, P., Harris-Huemmert, S., McAlpine, L., \& Wagstaff, S. (2011). The hidden realities of life as a doctoral student. In V. Kumar \& A. Lee (Eds.), Doctoral education in international context: Connecting local, regional and global perspectives (pp. 213-254). Malaysia: Universiti Putra Malaysia Press.

Jazvac-Martek, M., \& Colbeck, C. L (2008). Lost in translation: Learning professional roles through the situate curriculum. New Directions for Teaching and Learning, 113, 57-68.

Jazvac-Martek, M. (2009). Oscillating role identities: the academic experiences of education doctoral students. Innovations in Education and Teaching International, 4(3), 253-26.

LaBoskey, V.K. (2004). The Methodology of self-study and its theoretical underpinnings. In J. J. Loughran, M. L. Hamilton, V. K. LaBoskey, \& T. Russell (Eds.), International Handbook of Self-Study of Teaching and Teacher Education Practice (pp. 817-869). Springer.

Lave, J., \& Wenger, E. (1991). Situated learning: Legitimate peripheral participation. New York, NY: Cambridge University Press.

Louie, B. Y., Drevdahl, D. J., Purdy, J. M., \& Stackman, R. W. (2003). Advancing the scholarship of teaching through collaborative self-study. The Journal of Higher Education, 74(2), 150-171.

McAlpine, L., \& Amundsen, C. (2009). Identity and agency: pleasures and collegiality among the challenges of the doctoral journey. Studies in Continuing Education, 31(2), 109-125.

Pinnegar, S., \& Hamilton, M.L. (2009). Self-study of practice as a genre of qualitative research: Theory, methodology, and practice. Dordrecht, the Netherlands: Springer.

Pinto Zipp, G., Cahill, T., \& Clark, M. A. (2009). The role of collaborative scholarship in the mentorship of doctoral students. Journal of College Teaching \& Learning, 6(8), 29-35.

Rubin, H. J., \& Rubin, I. S. (2005). Qualitative interviewing: The art of hearing data. Thousand Oaks, CA: Sage.

Samaras, A. P., \& Freese, A. R. (2009). Looking back and looking forward: An historical overview of the self-study school. In C. A. Lassonde, S. Galman, \& C. Kosnik (Eds.), Self-study research methodologies for teacher educators (pp. 3-20). Rotterdam, The Netherlands: Sense Publishers. 
van Manen, M. (1990). Researching lived experience: Human science for an action sensitive pedagogy. Albany, NY: State University of New York Press.

Walker, G. E., Golde, C. M., Jones, L., Bueschel, A. C., \& Hutchings, P. (2008). The formation of scholars: Rethinking doctoral education for the twenty-first century. San Francisco, CA: Jossey-Bass.

Ward, M. H., \& West, S. (2008). Blogging PhD candidature: Revealing the pedagogy. International Journal of Emerging Technologies and Society, 6(1), 66-71.

Wright, L. L., Lange, E., \& Da Costa, J. (2009). Facilitating adult learning and a researcher identity through a higher education pedagogical process. US-China Education Review, 6(11), 1-16. 